\title{
Open Scholarship
}

Tobias Steiner

Open Scholarship as a paradigm consists of three dimensions:

1. Open output, comprising specific content / products from the fields of open publishing, open data, open source, open education, open access, and similar open movements.

2. Open practice, describing how those working in and with academia search and find, (co-)create and disseminate the elements of 1), such as e.g. open science practices for research-focused activities; open teaching and learning in its many facets including open educational practices and open pedagogy; citizen science; scholarly communication, outreach and collaboration.

3. Open networked participation, as a set of underlying practices that frame scholars' and other inolved parties' uses of digital technologies and that are informed by certain grounding assumptions and values regarding accessibility, democratization, justice and the assertion of fundamental human rights via the spread of equitable knowledge along its life-cycle of creation, dissemination and re-use along. Open networked participation is a process happening under constant negotiation of one's and others' personal, institutional, legal, and other social factors and resulting boundaries.

This definition is an adaption and remix of earlier definitory elements taken from Veletsianos and Kimmons (2012), Weller (2014), and DeRosa and Jhangiani (2018).

References

Veletsianos, George and Royce Kimmons. (2012). Assumptions and Challenges of Open Scholarship. The International Review of Research in Open and Distributed Learning, vol. 13 (4). 13 (4), 166-89. DOI: 10.19173/irrodl.v13i4.1313.

Weller, Martin. (2014). The Battle For Open: How openness won and why it doesn't feel like victory. DOI: 10.5334/bam.

DeRosa, Robin and Rajiv Jhangiani. (2018). What is Open Pedagogy? openpedagogy.org. 
